\title{
Transforming industrial value creation in aspect of sustainable technology digitialization
}

\author{
Elena Balashova $^{1}$ and Ksenia Maiorova ${ }^{1, *}$ \\ ${ }^{1}$ Saint-Petersburg State Marine Technical University, 3, Lotsmanskaya St., 190121, St. Petersburg, \\ Russia
}

\begin{abstract}
The purpose of this study is to identify and determine the transformation of the processes of creating the cost of industrial enterprises and the logistics sphere in the aspect of digitisation of organizational technologies. The authors determined the influence of organizational technologies on industrial products and logistics processes. The phenomenon of "digitisation" of value chains of industrial enterprises and logistics sphere and its specifics is considered. Analysis of creation of a digital value chain of an industrial enterprise of the automotive industry was carried out. Key factors determining the program of digital transformation of industrial enterprise are considered. The study was based on the scientific literature and publications on the issues raised in the field of transforming the processes of creating the cost of industrial enterprises in the aspect of digitisation of organizational technologies. In the context of Industry 4.0 development, traditional management is changing, and a new management concept is being considered, within the framework of which digitisation is the only tool for productivity growth and production stability. It was noted by the authors that for a more cautious and gradual transition from the old to the new one, the concept of "Transition Points," a course of change formulated by Accenture, should be applied. Partial digitization and the introduction of new digital business models together will give industrial enterprises and the logistics sector maximum growth in EBITDA and revenues. The study noted that to release the full potential of digitisation, companies should develop their own digital strategy, which will focus on five key factors: vision, roadmap, demand, team and solutions.
\end{abstract}

\section{Introduction}

The digital revolution and transformation in the industrial and logistics industries is one of the main global trends on which the fate of enterprises that create two-thirds of global GDP depends [1]. Currently, automakers, aircraft manufacturers, manufacturers of trains and household appliances, heavy engineering, instrument making, and the pharmaceutical industry, energy and mining companies are experiencing new technological shocks. Soon, high-tech industrial products and processes will be included, which will be interactive and managed by large amounts of data. Familiar things will become carriers of configurable

\footnotetext{
* Corresponding author: Mayorova@smtu.ru
} 
software that determines the range of available services and the final profitability of the product [2].

The introduction of production technologies involves a phased change in quality characteristics, processing of the environment, its shape, structure, material, and consumer properties. Most of the technologies can be considered productive since any of them is designed to improve the quality of the source resource. Full digitisation of value chains will help manufacturing enterprises and logistics grids get huge financial benefits. By "value chain" in terms of digitisation, authors mean a tool for determining a company's competitive advantage to build an enterprise's organizational system in accordance with its new digital business model.

A typical task of production technologies is to assess how much the process can meet the requirements set forth in regulatory documents. In most industrial industries, enterprise leaders are beginning to understand this. The bonus for the whole society will be the spread of value added beyond enterprises. Often, the public benefits of implementing digital business strategies overlap the growth in EBITDA and sales of enterprises themselves. To date, this indicator has become one of the popular indicators showing what income the business brought in the current period, and therefore it can be used to assess the profitability of investments and self-financing opportunities. For business, the significance of the value concept is that understanding it is essential for developing digitisation strategies. Digitisation at different speeds, for different directions and in different market segments can release unpredictable reserves of digital value [3]. Digitization of organizational technologies will help to streamline and improve relationships within the enterprise itself. This building of internal collaboration in the process of joint achievement of the set goals will make it possible to effectively manage the process within the organization, and, as a result, will allow to manage the result.

In connection with the above, we believe that the benefits of digitisation need to be investigated for two practical reasons: firstly, to economically justify the introduction of digitisation technologies in the internal business relations of the enterprise and logistics grids; secondly, more importantly, to show how digitisation leads to value creation. Technologies that have played a supporting role so far have become a source of tremendous efficiency and a powerful foundation for breakthrough innovation and value creation. [4] If the manufacturing process does not meet its specifications, then it is called defective, since a non-conformance situation occurs. The Six Sigma methodology applies to all areas of business and production, and in each of these areas they process and produce a variety of things.

Based on the above, the aim of the study is to identify and determine the transformation of the processes of creating the cost of industrial enterprises in logistics in the aspect of digitisation of organizational technologies. In connection with the established goal, it is necessary to solve the following tasks:

- Determine the impact of organizational technologies on industrial products and logistics processes in terms of digitisation;

- Consider the phenomenon of "digitisation" of the value chains of industrial enterprises and logistics grids, and its specifics;

- Analyze the value chain of the automotive industry;

- The key factors determining the program of digital transformation of the industrial enterprise are considered.

\section{Materials and Methods}

Digitization of technologies, because of the concept of Industry 4.0, which answers the question of how to create more with the same amount of resources, can free up considerable 
resources and reduce production losses. Multi-parameter hardware that is monitored by sensors shows a significant increase in performance, which can increase ROI. This depends on a decrease in the level of volatility in production when the same amount of resources gives a more stable result at the output.

Digitisation leads to changes in value creation processes, which in turn relates to the transformation of organizational and production technologies of enterprises. This study examines the problem of organizational technologies, where we manage the process and manage the result. Industry 4.0 depends on many factors, including digitisation of organizational technologies. We can say that this concept is a way to effectively plan production operations, and many Russian enterprises feel this. Digitisation of technology acts as a tool that allows you to determine as accurately as possible what resources will be required and how they can be optimized.

For industrial enterprises, the digital revolution will unfold on two main fronts. On the one hand, the application of new digital technologies will be required to increase the internal efficiency of all functions. This is the only way to free up funds to enter existing and future smart device markets. This is especially true for traditional industrial enterprises. Digitization of technology almost always allows you to free up hidden costs that can be invested in the future. On the other hand, digitisation will make companies understand how smart devices can create a market, what advanced, technology-driven and cost-creating relationships with customers should be and how to integrate all this into new, unusual models of creating results. We can confidently say that industrial enterprises that correctly implement their digital concept will achieve unheard of growth rates of profit. The increase in the productivity of industrial value creation processes currently depends on many factors, including the digitisation of organizational technologies.

The study was based on the scientific literature and publications on the issues raised in the field of transforming the processes of creating the cost of industrial enterprises in logistics in the aspect of digitisation of organizational technologies. In the context of Industry 4.0 development, traditional management is changing, and a new management concept is being considered, within the framework of which digitisation is the only tool for productivity growth and production stability. In the conditions of the new management, we do not compare whether there are costs or not, but we focus solely on whether a business will exist in new realities or not.

Based on the analysis of the above sources, the following assumptions were made:

- Traditional business in the past. Manufacturing companies will be able to make huge financial profits from digitising the entire value chain;

- Analysis of how to create value is critical for developing digitisation strategies. At different rates of adoption of digital technologies, a different scale of digital cost is created;

- Based on the example of the automotive industry, the authors found that investing in new digital business models will give companies an advantage and the opportunity to tap into the accumulated potential and become leaders.

\section{Results}

Digitisation can lead to the emergence of completely new value propositions to customers, new relationships with them, innovative models of income generation, new market access, more efficient business processes, etc. One of the most important effects of digitisation is that tangible products are replaced or expanded by intangible digital information that can be offered as services, and, as a result, digital technologies increase the cost of business by an average of five times faster than previously it was due to innovations in traditional technologies. A few years ago, Fortune 500 companies needed an average of about 20 years to exceed the capitalization bar (market value of the stock population) of a billion dollars 
[5], but today's digital startups earn unicorn status in just four years [6]. In 2013, this term "unicorn company," which cost more than $\$ 1$ billion, was coined by Cowboy founder Eileen Lee.

Note the larger the corporation, the exponentially higher the possible profit from its digital transformation. However, in the case of large companies, there is an old problem Titanic is exceedingly difficult to change course. Huge infrastructural and cultural changes must be made, the interests of many stakeholders should be considered, competing budgetary considerations should be considered in the light of falling profitability. The return on equity of manufacturers of industrial equipment has already fallen to several percent. The profitability of automakers, for example, is still about $10 \%$, but this is not enough to ensure the transition to business models based on digital technologies. The foundation itself is too weak to move to a new one. Obsolete non-digital infrastructure is still quite successful and replacing it can cause some problems. The technology being introduced can become too old, inefficient, or completely inoperative.

A vicious cycle of uncertainty confuses business leaders, and to find the right way to transform, it is important to learn how to analyze value. Digitisation of technology needs to be implemented carefully and gradually. To move from old to new, the concept of "Transition Point" is important - a reasonably designed course of change, which was formulated by Accenture, allowing companies to find new growth opportunities in the digital age, without abandoning their core business. Digitisation is possible if you increase the core business and increase its profitability in such a way that more and more investments are invested in innovation (Figure 1).

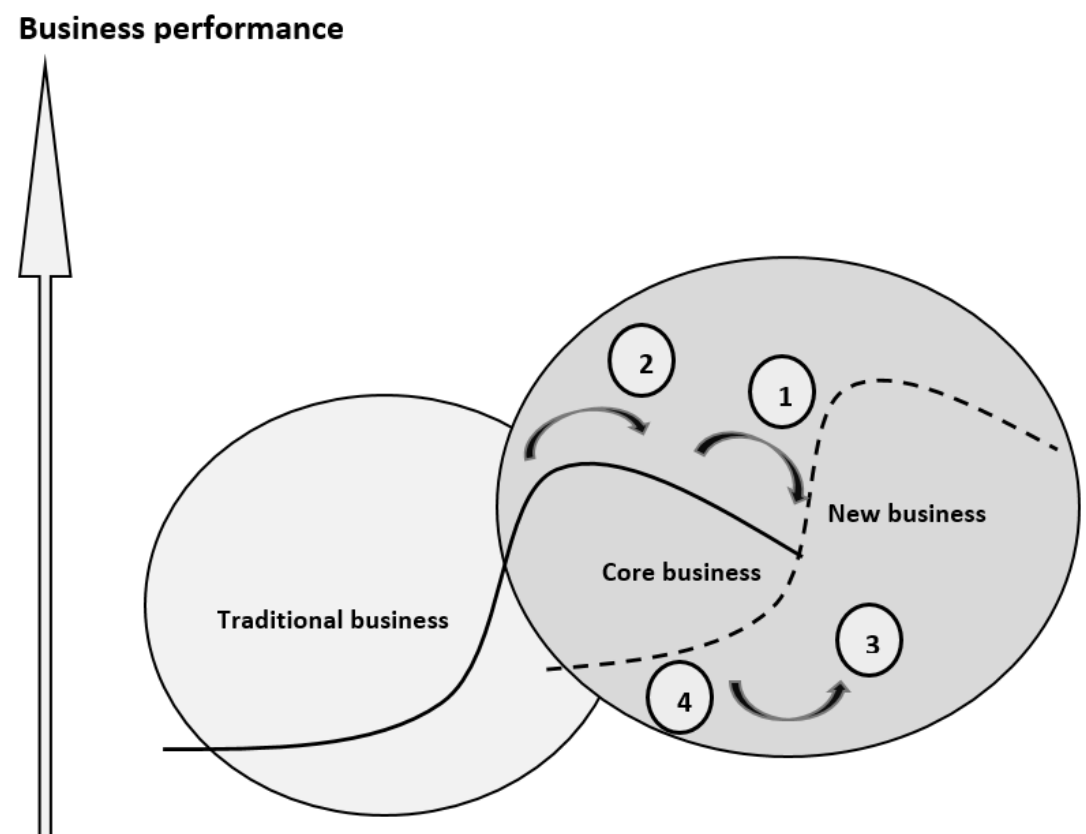

Time

Fig. 1. Transition Point - four weighted steps. (1 - Core Business Transformation; 2 - Growth of the core business; 3 - Innovation development; 4 - "Transition point.") [7]. 
This approach has basic value, but there is a difference between accidental, situational (ad hoc) introduction of innovations and strategic innovative development. It is based on real basic needs and is focused on progress, the purpose of which is to get more and more benefits from digitisation. It is easier to understand how much value can be gained from digitisation and where it is concluded, if you compare the gap between the speed of the emergence of technological innovations and the pace of their implementation, because technology does not know downtime. Continuously improved sensors, mobile data transmission capabilities; cloud services offer more and more specialized business solutions, the power of analytics tools is growing, which are becoming familiar working tools. The trajectory and pace of this intellectual work are completely unrelated to the dynamics of the work of the enterprises for which they are created. Autonomous digitalized automated production has already appeared - profitable industrial enterprises that can automatically fulfill orders, but most industries that need to adopt such a radical technological approach are still extremely far from that.

This situation is since justifying the benefits of breakthrough innovations and introducing them into business practice is no easier than creating. Business always lags the development of technology, which is almost inevitable, but it is thanks to this gap that the potential for cost growth becomes visible, which will free up the introduction of innovation. Since the progress of digital technologies is at great speed, such a reserve of value for society and enterprises has already become gigantic. If the industry were to introduce digital technologies at least three times slower than they appear, the cost to the business that they could receive would be huge.

General calculations based on detailed screening of different sectors made it possible to estimate the potential cost existing in different industries. The total value that these industries can achieve by 2025 through the introduction of digital technologies will be $\$ 100$ trillion worldwide [8]. Such a result has a remarkably interesting structure: a fifth of the hidden cost is concentrated in only four sectors: automotive, light industry, energy, and logistics. Thus, digitisation of technology could increase the operating profit of electricity producers by almost $50 \%$ [9].

Digital technology does create significant reserves of profit for manufacturing and service enterprises and their internal functions. However, there is also a useful side effect they produce significant benefits for society. Value to society often exceeds what digitisation creates for business. For example, the huge social problem is that humanity is simply not able to bring the population growth rate and their requirements for living standards into line. A good example is logistics. If you look at how aviation, rail or road transport works, it becomes quite obvious that it is impossible to continue working in the existing realities. After all, digitisation can give incredibly significant potential benefits to the logistics sector. Retail and wholesale transportation and delivery services generate $13 \%$ of all environmental emissions worldwide. Digitisation makes it possible to reduce such emissions by $11 \%$ over the next 10 years. In the long term, harmful emissions can be reduced by $90 \%$ and about a quarter optimize the expenses of the "last mile," that is, at the site of direct delivery of the package to the client, using the technology of digital unmanned aerial vehicles (drones) and unmanned vehicles. They have every chance of becoming a serious cost generator for society.

In general, worldwide in 2017, the total revenue of parcel delivery firms exceeded $\$ 350$ billion. The United States, and in developed countries such as the United States and Germany, increased from 7 to $10 \%$. If these companies were able to save, for example, on drivers of delivery vans, their expenses would decrease even more noticeably than in the case of large-scale trucks. Drivers pay accounts for about $60 \%$ of total costs, and today industry players are looking for ways to reduce these costs. Already, this situation is changing, as small electric car versions of classic delivery vans (AGV), namely, a ground- 
based autonomous vehicle, will soon appear. In our case, it is a "smart" version of a delivery van with cells located on the sides, the dimensions of which correspond to the dimensions of the parcels. It is necessary to look after the work of the AGV, but the scope of observation can be easily expanded - one dispatcher will be able to control the operation of 8-10 such machines at the same time.

Autonomous driving systems will appear the fastest in countries with the highest salaries. In this regard, logistics companies in the USA and European countries have already begun to develop appropriate strategies, considering the time required to build the necessary human resources and attract IT resources. In addition, considerable investment is needed to achieve some success in a changing environment. Well-established companies can be given a good boost by such vigorous investments. After all, if they take control of their entire supply chain - container transportation, road transportation of goods to distributed centers and direct delivery to the client - then traditional industry players will lose a significant part of their income, which will limit their ability to further investment and innovation.

Business examples can be grouped into clusters where value creation for society and the enterprise is equally high and where the ratio is strongly shifted towards one or the other. Over time, this ratio may change, for example, in the case of autonomous cars, the public benefit is initially extremely high, and there is almost no immediate benefit for car manufacturers, although it may appear later. There are many examples for the benefits of society, and by analyzing them, we conclude that digital technologies can indeed partially solve the very pressing problems of humanity.

What is the measurable impact that digital technologies have on business performance indicators such as EBITDA, sales, balance sheet, profit and loss? In study, we will focus on only one market segment - the automotive industry, since this industry is a complex, international structure that has a special multiplier effect on other industries; and due to the fact that one of the key features distinguishing the mechanism of supply chains in the automotive industry from other industries is the work with specific supply schedules. These observations will reveal some basic guidelines for all other industries as well.

The automotive industry is a good example for research, as it was one of the first to introduce automation and digitisation technologies such as CAD and EDI in the field of design and production. Already in the 1970s the automotive industry created robots with numerical software control, thanks to which it received a huge increase in efficiency. And since then, it has continued to increase cost, updating production and business technologies - from one wave of innovation to another. Nevertheless, the hidden cost of this industry, which digitisation can release, remains significant. This is especially important because when the car becomes part of a service platform within the wider ecosystem, the industry again must radically change its mode of operation.

\subsection{The automotive industry is at the forefront of progress}

Currently, the automotive industry is undergoing radical changes, which, on the one hand, are caused by the influence of Industry 4.0 on digitisation of products and technologies, and on the other, are due to the emergence of new approaches to business process management. According to a McKinsey study, global revenue from the automotive industry will grow by an average of $4.4 \%$ annually and reach about $\$ 6.7$ trillion by 2030 . The United States, and the share of traditional technologies and business models, which now accounts for $98 \%$ of the market, will decrease to $50 \%$.

Current trends show not only the desire of the automotive industry for digitisation, but also that digitisation is inevitable, thanks to the cost it carries, as well as the trends of the 
surrounding ecosystem. The automotive industry is expected to face five major trends over the next five years:

1. the more the internal operation of the car will depend on digital algorithms, the more there will be mismatches in the development cycles of hardware and software. This phenomenon is common in other industries and is not easy to manage;

2. the deterioration of the environmental situation will force automakers to create engines that produce less and less harmful emissions. But this is impossible without extremely accurate software control of various parts of the engine. Therefore, it will soon be impossible to do without digital components and software;

3. the function of the car as a vehicle will change. A car connected to the network will become a device equipped with regularly updated, rapidly developing software packages. Automakers will have to learn advanced data analytics and secure processing of large amounts of confidential information;

4. the car will not remain a simple vehicle for transporting people and goods that are not connected to the network. To maintain the appropriate level of competitiveness among automakers, it will become extremely important to use the technologies of digitalized cars and shared use. Cars will interact with each other and function as part of fleets, they will become part of the ubiquitous concept of freedom of movement. Digital technologies are not just vital for "conducting" such a complex transport ensemble - without them all this is impossible;

5. since the car will remain a consumer product, it will experience new rules of customer loyalty in the era of hyperconnection. Automotive brands will have to work harder with customers, transforming their offline and online experiences into loyalty.

Based on the above, we conclude that car manufacturers who have chosen digitisation and create fully digitalized business models will increase their global turnover by $15.6 \%$, or $\$ 216$ billion, by 2020 inclusive. The increase in profitability that digital technologies bring is very impressive. We assume that the total EBITDA for automotive companies will grow by $42.8 \%$, or $\$ 59$ billion [11]. By 2021 , the full potential will be realized by digitizing customer experience and internal operations in the existing value chain. Further growth in subsequent years can be achieved only by completely changing existing business models to new ones, namely, digitalized ones.

To systematically invest in digital technologies is quite logical for the automotive industry. For clarity, let us consider an example of investing in the most modern digital business models for an automaker with an annual turnover of $\$ 50$ billion [12]. If you implement the "car as a service" approach, car rental or sharing models, or even an intermodal transport platform, connecting various modes of transport, such as trains, airplanes, buses, bicycles and cars, this will help earn only \$260 million in underdeveloped markets [13]. Solutions for connected cars, for certain transport services, or a platform for open transport applications, will provide a modest $\$ 35$ million [14]. Similarly, there is no significant demand for autonomous car services yet, consumer data will be sold on premium or life and health service platforms in relation to specific car brands. In our opinion, this will increase EBITDA by only $\$ 10$ million [15].

Suppose that we managed to go through part of the step-by-step digitisation, and in one operation we implemented all the latest business models for the automotive industry. In this case, the total EBITDA gain over the next four years will not exceed a modest $6 \%$, or $\$ 325$ million. That is, 20 million less than what can be obtained from digitisation of various types of activities supporting business, with a partial digital approach [16]. In general, we conclude that those who focus on digitisation of internal operations and customer experience will achieve the maximum gain - their EBITDA will increase by $36.3 \%$, or by $\$ 1.815$ billion [17]. 
Until 2021, the largest cost in the automotive industry can be created not by throwing its head at a digital space, but by partially digitising the creation chain based on traditional business models. This is partly since outdated infrastructure and traditional processes are still able to create cost quite successfully. In addition, consumer markets are not yet sufficiently developed to implement business models of the future. The time for fullfledged digitalized production with new business models and the provision of services will begin during the 2020 s.

\section{Discussion}

The introduction of digital technologies within the framework of the concept of Industry 4.0 creates the prerequisites for the formation of a new, digital economy, which is already beginning to be realized at a growing pace. To prepare, it is necessary to create a solid digital basis that can gradually be expanded. As mentioned above, there are two value chains - the main and the new. Invest in both, gradually switching from the first to the second. You should begin digitizing the existing creation chain, and work in parallel on new business models that will operate under the control of software. It is also worth paying special attention to the previous value chain, as it will provide the financial resources necessary for investing in the development of a new business model. When a full-fledged economy of result manifests, new production models will already be ready. To improve the investment strategy, it is necessary to find out how much investment in various areas of activity can bring.

However, not all directions have the same prospects. Estimating the hidden cost of individual functions in automotive companies gives a very heterogeneous picture. The digital value chain consists of separate functions and steps. The model was calculated for the automaker with an annual turnover of $\$ 50$ billion and the following results were obtained [18]:

1) marketing, sales, and after-sales service.

Digitisation will bring the most cost to marketing and sales, increasing their volumes by $14.3 \%$, or more than $\$ 715$ million, in the partial digitisation scenario. After-sales service will bring an additional $\$ 225$ million [19]. Obviously, this is not the main production activity. The results are not so unexpected. Especially when you consider how much potential there is for innovation. These are personalized service offerings based on predictive analytics, direct online sales, point of sale digitisation, new digital marketing channels, digitalized advertising and centralized digital content management of websites and social media platforms. The analysis showed that the proposed automotive business can and should benefit in the short term from investments in these areas.

2) $R$ \& D, design, and production.

The main engineering and production segments of the automotive business are the next in terms of value reserves. Better organization of supply chains, digitalized control assembly lines, individual improvements to various production processes in the workshops, increased use efficiency. All this contributes to a significant increase in the cost created by production. Collaborative robots ("cobots") are expected to increase performance by $71 \%$, and smart helmets and other augmented reality devices - by $56 \%$ [20]. The EBITDA growth of the model enterprise thus amounted to more than $\$ 715$ million in production and $\$ 115$ million in development and design. The total cost is thus increased by $8.3 \%$.

3) Business support functions.

It is noteworthy that the tasks of human resources management, IT support, procurement and financial management always benefit in one way or another from the introduction of digital technologies, such as robotization or blockchain. Estimating the 
model of an automobile company, the corresponding increase in value was found by almost $7 \%$, or 345 million dollars [17].

Although the hidden reserves of the process of creating hidden values vary greatly from industry to industry, the following conclusions are formulated. The first conclusion: doing business without changes cannot be a strategic option for a sustainable and profitable business. It is equivalent to losses of income, market share, EBITDA, competitiveness, and for public companies - and a decrease in shareholder value. Recall that an automaker with an income of $\$ 50$ billion, which is not engaged in digitalization, risks an EBITDA of $\$ 780$ million and misses a profit of \$2.14 million until 2021 [21].

The second conclusion: do not choose between partial digitisation and the introduction of new digital business models - it is better to do both. Initial investment in new business models is the best way to counter the effect of cannibalization and create the basis for those business models that will dominate the industry. New digital business models and partial digitisation do not contradict each other. On the contrary, if you do both, then the potential for future growth in terms of EBITDA and income will increase as much as possible. Returning to the example of the automotive industry, with a turnover of $\$ 50$ billion, its EBITDA growth potential is $\$ 1.8$ billion $(36.3 \%)$ due to partial digitisation and an additional $\$ 325$ million $(6.5 \%)$ due to the introduction of new business models $[22,23]$.

Conclusion three: Create your own digital strategy to release digitisation potential. Digitisation enthusiasts focus on the five key drivers of their digital transformation program (Figure 2) vision, roadmap, demand, team, and solutions.

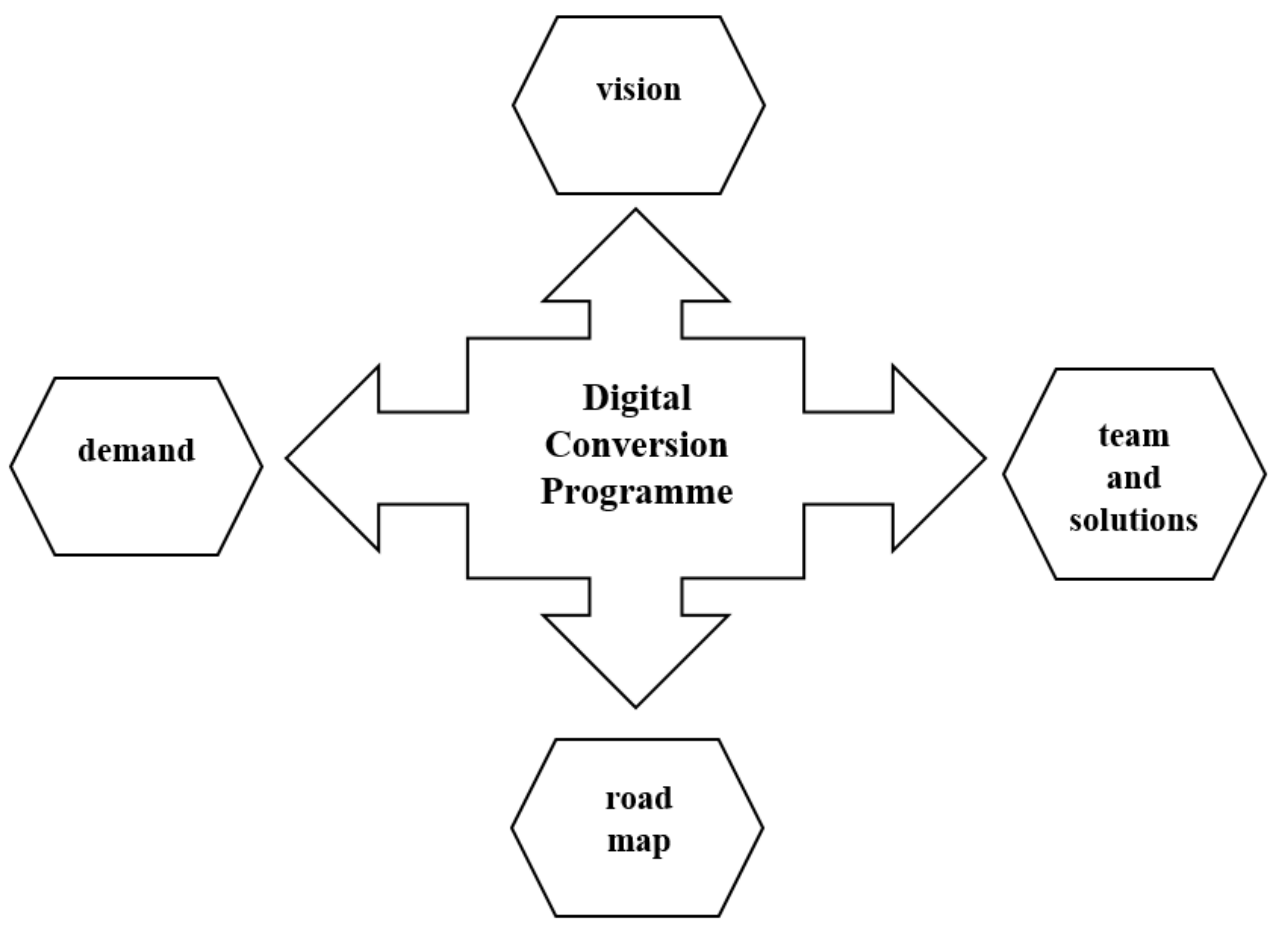

Fig. 2. Five key factors determining the digital conversion program [24, 25].

Effective digital strategies should adapt to the individual characteristics of the organization, using its strengths so as not to miss opportunities, while controlling potential risks. It is necessary to investigate in detail the different strategy options and their 
associated potential EBITDA values by performing cost-effectiveness analyses for each option.

\section{Conclusions}

Smart digitisation strategy, implemented at the right time, can change the situation - it all comes down to finding transition points in areas that form the basis of the business. Digitisation will strengthen it and provide a financial opportunity to increase operational efficiency to finally launch innovations by creating financial efforts. As a result, this will provide financing for the development and implementation of new business models and new types of income from products and services connected to the network.

Findings of the study:

1. The authors noted that the level of possible profit of the company from its digital transformation directly depends on its scale. Having considered the example of the automotive industry, they concluded that the basis for the transition to digital business models is still too weak. Therefore, the concept of "Transition Points," which is the course of change that Accenture has formulated, can be applied to move more cautiously and gradually from the old to the new.

2. Manufacturers of cars that have chosen digitisation and create fully digitalized business models will increase the total turnover worldwide by $15.6 \%$, or by $\$ 216$ billion, by 2020 inclusive.

3. Until 2021, the largest cost in the automotive industry and logistics can be created by partially digitising the creation chain based on traditional business models. This is because outdated infrastructure and traditional processes are still able to create value quite successfully. In addition, consumer markets are not yet sufficiently developed to implement business models of the future.

4. A strategic option for a sustainable and profitable business is the adoption of new trends in the conditions of digitisation of technologies and the transition to new, digital business models.

5. Partial digitisation and introduction of new digital business models together can give industrial enterprises maximum growth in EBITDA and revenue, which was considered on the example of the automotive industry and ligistics.

6. To unlock the full potential of digitisation, companies are invited to develop their own digital strategy, which will focus on five key factors: vision, roadmap, demand, team, and solutions.

In the end, digitisation of technologies, as a result of Industry 4.0, gave impetus and continues to stimulate industrial production not only to realize the formation of a new management concept, where digitalization acts as a tool for productivity growth and production stability, but also to address the important challenges of creating a new digital value chain, Since the new environment in which enterprises are forced to exist is characterized by the need to flexibly adjust and modify existing business models. The introduction of digitisation technologies into the business structure of industrial enterprises, their logistics networks and value chains - all this creates the prerequisites for the development of new, digital business models of enterprises in modern conditions.

\section{References}

1. V.V. Akberdina, News of the Ural State Economic University 19(3), 82 - 99 (2018)

2. E.S. Balashova, I.P. Krasovskaya, E.A. Malyshev, F.A. Shamrai, ZabSU Bulletin 3, 80-89 (2020) 
3. E.S. Balashova, K.S. Maiorova, Economic sciences 12(2), 84-91 (2019)

4. Yu.V. Vertakova, T.O. Tolstoy, E.V. Shkarupeta, V.V. Dmitrieva, Transformation of management systems under the influence of digitisation of the economy: monograph (Publishing House of SUSU, Kursk, 2017)

5. E. Schaeffer, Industry X.0 Advantages of Digital Technology for Production (Publishing group "Point", 2019)

6. S. Maydanova, I. Ilin, Proceedings of the 33rd International Business Information Management Association Conference, IBIMA 2019: Education Excellence and Innovation Management through Vision 2020 (2019)

7. Accenture, https://www.accenture.com/us-en/ /media/Accenture/next-gen/openinnovation/pdf/Accenture-Bridgemakers-Guiding-Enterprise-Disruption.pdf

8. T.A. Golovina, A.V. Polyanin, O.V. Rudakova, Economics and Management 2, 13-18 (2017)

9. V. Kulagin, A. Sukharevsky, J. Meffert,Digital@ Scale: Desktop book on digitisation business (Intellectual literature, 2020)

10. The Center for Global Enterprise, https://www.thecge.net/app/uploads/2016/01/PDFWEB-Platform-Survey_01_12.pdf

11. Accenture, https:/www.accenture.com/t20160506T052209_w_/usen/_acnmedia/PDF-13/Accenture-Connected-Industrial-Workforce-Research.pdf

12. E.S. Balashova, K.S. Maiorova, Contradictions and trends in the development of the modern Russian society Collection of scientific articles of the All-Russian Scientific and Practical Conference 2, 32-43 (2019)

13. M. Hammer, Faster, better, cheaper: Nine methods of reengineering business processes (Alpina Pable., 2012)

14. E.A. Malyshev, A.V. Babkin, Digital economy and Industry 4.0: trends 2025. Collection of works of scientific and practical conference with international participation (2019)

15. V.A. Plotnikov, S.P. Koida, Economics and management 1(99), 30-35 (2014)

16. K. Schwab, The Fourth Industrial Revolution (Publishing House "E", 2017)

17. S.A. Dyatlov, N.I. Didenko, O.S. Lobanov, S.V. Kulik, IOP Conference Series: Earth and Environmental Science 3, 13-27 (2019)

18. Jinesh Kumar Jain, G.S. Dangayach, G. Agarwal, International Journal of Engineering Technology and Management (IJETM) 1, 40-43 (2014)

19. Amandeep Saini, Surbhi Sahu, Sonali Rathod, Harpreet Saini, International Journal of Engineering Technology and Management (IJETM) 1, 1-6 (2014)

20. Y. Malhotra, SSRN Electronic Journal (2015)

21. Jaideep Singh, International Journal of Engineering Technology and Management (IJETM) 4, 18-22 (2017).

22. P.K. Hirani, International Journal of Engineering Technology and Management (IJETM) 2, 1-7 (2017)

23. T. Ahern, P. Byrne, B. Leavy, International Journal of Managing Projects in Business 8(4), 732-754 (2015)

24. B. Alshehhi, D. Thorpe, S. Goh, S. Alkaabi, International Journal of Engineering Technology and Management (IJETM) 5.6, 201-213 (2018)

25. J. Wang, C. Yang, International Journal of Production Economics 135(2), 823-831 (2019) 